Pacific Journal of Mathematics

A NOTE ON ABELIAN GROUP EXTENSIONS 


\section{A NOTE ON ABELIAN GROUP EXTENSIONS}

\section{R. J. NUNKE}

In Exercise 21 page 248 of his book Abelian Groups L. Fuchs asks for a proof of the following

THEOREM. If $A$ is a torsion-free and $C$ a torsion group, then $\operatorname{Ext}(A, C)$ is either 0 or contains an element of infinite order.

Unfortunately the hint given with the exercise leads only to the conclusion that every countable subgroup of $A$ is free. Professor Fuchs has informed me that he meant to assume $A$ countable. The purpose of this note is to prove this theorem.

Lemma. If $C_{1}, C_{2}, \cdots$ is a sequence of abelian groups, $\Pi C_{i}$ their direct product and $\Sigma C_{i}$ their direct sum, then $\operatorname{Ext}\left(A, \Pi C_{i} / \Sigma C_{i}\right)=0$ for all torsion-free groups $A$.

Proof. A special case of this lemma with all the $C_{i}=Z$ the group of integers is a consequence of Theorem 1 of [1]. The proof of the special case given in [4] makes no use of the fact that $C_{i}=Z$. This proof will be sketched here. It is enough to prove the case in which $A$ is the rational numbers. Since $\operatorname{Ext}\left(A, \Pi C_{i} / \Sigma C_{i}\right)$ is a homomorphic image of $\operatorname{Ext}\left(A, \Pi C_{i}\right)$ we must show that each extension $0 \rightarrow \Pi C_{i} \rightarrow$ $E \rightarrow A \rightarrow 0$ splits over $\Pi C_{i} / \Sigma C_{i}$, i.e., that there is a map $f: E \rightarrow \Pi C_{i} / \Sigma C_{i}$ whose restriction to $\Pi C_{i}$ is the canonical projection. With $A$ the rationals we choose elements $e^{1}, e^{2}, \cdots$ in $E$ such that $e^{n}$ maps onto $1 / n$ ! modulo $\Pi C_{i}$. Then $E$ is generated by $\Pi C_{i}$ and the $e$ 's with relations

$$
e^{n}=(n+1) e^{n+1}+c^{n} \quad n=1,2, \cdots
$$

where $c^{n} \in \Pi C_{i}$. We choose $b^{n} \in \Sigma C_{i}$ such that the first $n$ coordinates of $c^{n}+b^{n}$ are 0 and put

$$
x^{n}=\sum_{k \geqq n}(k ! / n !)\left(c^{k}+b^{k}\right) .
$$

Then

$$
x^{n}=(n+1) x^{n+1}+c^{n}+b^{n}
$$

and we can define $f$ to be the projection on $\Pi C_{i}$ and by $f\left(e^{n}\right)=x^{n}+\Sigma C_{i}$.

Proposition. If $C$ is the direct sum of infinitely many copies of

Received April 25, 1962. This work was supported by the National Science Foundation research grant NSF-G 11098. 
$D$ and if $A$ is torsion-free with $\operatorname{Ext}(A, D) \neq 0$, then $\operatorname{Ext}(A, C)$ has an element of infinite order.

Proof. Since $D$ is a direct summand of $C$ we have $\operatorname{Ext}(A, C) \neq 0$. The sequence

$$
\operatorname{Ext}(A, \Sigma C) \rightarrow \operatorname{Ext}(A, \Pi C) \rightarrow \operatorname{Ext}(A, \Pi C / \Sigma C) \rightarrow 0
$$

is exact where $\Sigma C$ is the direct sum and $\Pi C$ the direct product of countably many copies of $C$. By the lemma $\operatorname{Ext}(A, \Pi C / \Sigma C)=0$ so that the left-most map in the sequence is an epimorphism. Since $A$ is torsion-free $\operatorname{Ext}(A, C)$ is divisible and hence has elements of arbitrarily large finite order if it has nonzero elements of finite order at all. Hence $\operatorname{Ext}(A, \Pi C) \cong \Pi \operatorname{Ext}(A, C)$ has an element of infinite order. It follows that $\operatorname{Ext}(A, \Sigma C)$ also has an element of infinite order. Since $C$ is the direct sum of infinitely many copies of $D$ we have $\Sigma C \cong C$ so that $\operatorname{Ext}(A, \Sigma C) \cong \operatorname{Ext}(A, C)$ proving the proposition.

Now to prove the theorem we suppose that $A$ is torsion-free, $C$ is torsion and that $\operatorname{Ext}(A, C)$ is a nonzero torsion group. Then $\operatorname{Ext}(A, C)$ has a nonzero $p$-primary component for some prime $p$. Since $C=C^{\prime} \oplus E$ where $C^{\prime}$ is the $p$-primary component of $C$ and $E$ is the sum of the other primary components we have

$$
\operatorname{Ext}(A, C)=\operatorname{Ext}\left(A, C^{\prime}\right) \oplus \operatorname{Ext}(A, E) .
$$

Multiplication by $p$ is an automorphism of $E$, hence also an automorphism of $\operatorname{Ext}(A, E)$. It follows that $\operatorname{Ext}\left(A, C^{\prime}\right)$ is a nonzero torsion group. Hence in proving the theorem we may assume that $C$ is $p$ primary.

In [3] it was shown that, for $A$ torsion-free and $C p$-primary,

$$
\operatorname{Ext}(A, C) \cong \operatorname{Ext}(A, M)
$$

where $M$ is a direct sum of copies of $\Sigma Z / p^{n} Z$, the number of copies being equal to the final rank of $C$. If $C$ has bounded order, then $\operatorname{Ext}(A, C)=0$ for all torsion-free groups $A$. Otherwise the final rank of $C$ is infinite. This last case is the one to be considered. Then $M$ is the direct sum of countably many copies of itself and the proposition shows that $\operatorname{Ext}(A, M)$ is either 0 or has an element of infinite order.

The referee has pointed out that a stronger form of the lemma in this paper has been proved by A. Hulanicki (Bull. Acad. Pol. Sci. Ser. Sci. Math. Astr. Phys., 10 (1962), 77-80.) He showed that each element of infinite height in $\Pi C_{i} / \Sigma C_{i}$ is in the maximal divisible subgroup, hence this group is algebraically compact. 


\section{REFERENCES}

1. S. Balcerzyk, On factor groups of some subgroups of a complete direct sum of in finite cyclic groups, Bull. Acad. Polon. Sci. Ser. Sci. Math. Astr. Phys., 7 (1959), 141-142.

2. L. Fuchs, Abelian Groups, Budapest, Publishing house of the Hungarian Academy of Sciences, 1958.

3. R. J. Nunke, On the extensions of a torsion module, Pacific J. Math., 10 (1960), 597606.

4. - Slender groups, Acta Sci. Math. Szeged, 23 (1962), 67-73.

UNIVERSITY OF WASHINGTON 



\section{PACIFIC JOURNAL OF MATHEMATICS}

\section{EDITORS}

\author{
Ralph S. Phillips \\ Stanford University \\ Stanford, California \\ M. G. Arsove \\ University of Washington \\ Seattle 5 , Washington
}

\author{
A. L. Whiteman \\ University of Southern California \\ Los Angeles 7, California \\ Lowell J. Paige \\ University of California \\ Los Angeles 24, California
}
E. F. BECKENBACH
D. DERRY
ASSOCIATE EDITORS
T. M. CHERRY
M. OHTSUKA
H. L. ROYDEN
E. G. STRAUS
E. SPANIER
F. WOLF

\section{SUPPORTING INSTITUTIONS}

\author{
UNIVERSITY OF BRITISH COLUMBIA \\ CALIFORNIA INSTITUTE OF TECHNOLOGY \\ UNIVERSITY OF CALIFORNIA \\ MONTANA STATE UNIVERSITY \\ UNIVERSITY OF NEVADA \\ NEW MEXICO STATE UNIVERSITY \\ OREGON STATE UNIVERSITY \\ UNIVERSITY OF OREGON \\ OSAKA UNIVERSITY \\ UNIVERSITY OF SOUTHERN CALIFORNIA
}

\author{
STANFORD UNIVERSITY \\ UNIVERSITY OF TOKYO \\ UNIVERSITY OF UTAH \\ WASHINGTON STATE UNIVERSITY \\ UNIVERSITY OF WASHINGTON \\ AMERICAN MATHEMATICAL SOCIETY \\ CALIFORNIA RESEARCH CORPORATION \\ SPACE TECHNOLOGY LABORATORIES \\ NAVAL ORDNANCE TEST STATION
}

Mathematical papers intended for publication in the Pacific Journal of Mathematıcs should be typewritten (double spaced), and the author should keep a complete copy. Manuscripts may be sent to any one of the four editors. All other communications to the editors should be addressed to the managing editor, L. J. Paige at the University of California, Los Angeles 24, California.

50 reprints per author of each article are furnished free of charge; additional copies may be obtained at cost in multiples of 50 .

The Pacific Journal of Mathematics is published quarterly, in March, June, September, and December. Effective with Volume 13 the price per volume (4 numbers) is $\$ 18.00$; single issues, $\$ 5.00$. Special price for current issues to individual faculty members of supporting institutions and to individual members of the American Mathematical Society: $\$ 8.00$ per volume; single issues $\$ 2.50$. Back numbers are available.

Subscriptions, orders for back numbers, and changes of address should be sent to Pacific Journal of Mathematics, 103 Highland Boulevard, Berkeley 8, California.

Printed at Kokusai Bunken Insatsusha (International Academic Printing Co., Ltd.), No. 6, 2-chome, Fujimi-cho, Chiyoda-ku, Tokyo, Japan.

PUBLISHED BY PACIFIC JOURNAL OF MATHEMATICS, A NON-PROFIT CORPORATION

The Supporting Institutions listed above contribute to the cost of publication of this Journal, but they are not owners or publishers and have no responsibility for its content or policies. 


\section{Pacific Journal of Mathematics}

\section{Vol. 12 , No. 4 \\ April, 1962}

Tsuyoshi Andô, On fundamental properties of a Banach space with a cone ..... . 1163

Sterling K. Berberian, A note on hyponormal operators ................ 1171

Errett Albert Bishop, Analytic functions with values in a Frechet space . . . . . . . 1177

(Sherman) Elwood Bohn, Equicontinuity of solutions of a quasi-linear equation ............................................ 1193

Andrew Michael Bruckner and E. Ostrow, Some function classes related to the class of convex functions . . . . . . . . . . . . . . . . . . . . . . . . 1203

J. H. Curtiss, Limits and bounds for divided differences on a Jordan curve in the complex domain . . ................................. 1217

P. H. Doyle, III and John Gilbert Hocking, Dimensional invertibility . . . . . . . . 1235

David G. Feingold and Richard Steven Varga, Block diagonally dominant matrices and generalizations of the Gerschgorin circle theorem ................. 1241

Leonard Dubois Fountain and Lloyd Kenneth Jackson, A generalized solution of the boundary value problem for $y^{\prime \prime}=f\left(x, y, y^{\prime}\right) \ldots \ldots \ldots \ldots \ldots \ldots \ldots \ldots \ldots$

Robert William Gilmer, Jr., Rings in which semi-primary ideals are primary. . . . . 1273

Ruth Goodman, K-polar polynomials .......................... 1277

Israel Halperin and Maria Wonenburger, On the additivity of lattice completeness ........................................... 1289

Robert Winship Heath, Arc-wise connectedness in semi-metric spaces . . . . . . . . 1301

Isidore Heller and Alan Jerome Hoffman, On unimodular matrices . . . . . . . . . . . 1321

Robert G. Heyneman, Duality in general ergodic theory . . . . . . . . . . . . . . . 1329

Charles Ray Hobby, Abelian subgroups of p-groups . . . . . . . . . . . . . . . 1343

Kenneth Myron Hoffman and Hugo Rossi, The minimum boundary for an analytic

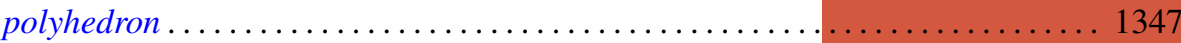

Adam Koranyi, The Bergman kernel function for tubes over convex cones ........ 1355

Pesi Rustom Masani and Jack Max Robertson, The time-domain analysis of a continuous parameter weakly stationary stochastic proces.

William Schumacher Massey, Non-existence of almost-complex structures on

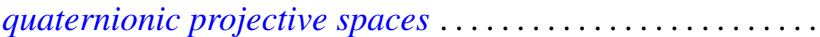

Deane Montgomery and Chung-Tao Yang, A theorem on the action of $\mathrm{SO}(3) \ldots . .1385$

Ronald John Nunke, A note on Abelian group extensions . . . . . . . . . . . . . 1401

Carl Mark Pearcy, A complete set of unitary invariants for operators generating finite $W^{*}$-algebras of type $I$

Edward C. Posner, Integral closure of rings of solutions of linear differential equations.

Duane Sather, Asymptotics. III. Stationary phase for two parameters with an application to Bessel functions.

J. Śladkowska, Bounds of analytic functions of two complex variables in domains

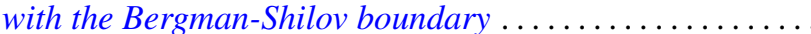

Joseph Gail Stampfli, Hyponormal operators .

George Gustave Weill, Some extremal properties of linear combinations of kernels

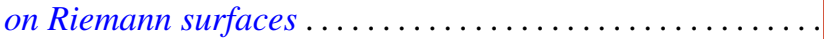

